\title{
Waves in shallow water off west coast of India during the onset of summer monsoon
}

\author{
V. Sanil Kumar ${ }^{1}$, C. Sajiv Philip ${ }^{1}$, and T. N. Balakrishnan Nair ${ }^{2}$ \\ ${ }^{1}$ Ocean Engineering Division, National Institute of Oceanography (Council of Scientific \& Industrial Research), Dona Paula, \\ Goa 403 004, India \\ ${ }^{2}$ Indian National Centre for Ocean Information System (Ministry of Earth Sciences), P.O. 21, IDA-Jeedimetla, \\ Hyderabad - 72, India
}

Received: 11 November 2009 - Revised: 11 March 2010 - Accepted: 17 March 2010 - Published: 19 March 2010

\begin{abstract}
The wave growth characteristics during the onset of summer monsoon in a swell dominated open ocean at a location off the west coast of India at $14 \mathrm{~m}$ water depth are studied. $67 \%$ of the measured waves are due to the swells arriving from south and south-west and the balance was due to the seas from south-west to north-west. Wave age of the measured data indicates that the measured waves are young sea with presence of swells. Even when the wind speed reduced to less than $3 \mathrm{~m} / \mathrm{s}$, significant wave height more than $2 \mathrm{~m}$ is present due to the swells in the Arabian Sea. The maximum wave height increased from 2 to $8 \mathrm{~m}$ within $60 \mathrm{~h}$. The mean wave directions at the high frequencies align with the westerly wind direction and gradually shift to south-westerly swell direction at low frequencies during the wave growth. The strong westerly winds present between longitude $72^{\circ}$ and $72.5^{\circ}$ at latitude $12.5^{\circ}$ has created the high waves $\left(H_{\mathrm{m} 0}\right.$ upto $5.65 \mathrm{~m}$ ) during the measurement period.
\end{abstract}

Keywords. History of geophysics (Ocean sciences)

\section{Introduction}

The wave height along the west coast of India is influenced by the wind conditions in Indian Ocean and Arabian Sea. Wind conditions in the Indian Ocean and Arabian Sea increase during mid May and high winds are observed upto September which is the period of the summer monsoon. Along the west coast of India, significant wave height up to $6 \mathrm{~m}$ is reported during the summer monsoon period (Kumar et al., 2006) and the significant wave height $\left(H_{\mathrm{m} 0}\right)$ will be

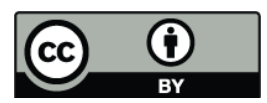

Correspondence to: V. Sanil Kumar (sanil@nio.org) normally less than $1.5 \mathrm{~m}$ during rest of the period (Kumar and Anand, 2004). The wave energy spectra generally have more than one peak depending on the generation source and also the waves at any point in the ocean will be sum of local wind sea and swell components propagating from distant storms (Hanson and Phillips, 1999). Kumar et al. (2003) found that along the Indian coast, about $60 \%$ of the wave spectra observed was multi-peaked and they were mainly single peaked when the $H_{\mathrm{m} 0}$ was more than $2 \mathrm{~m}$. The double peaked spectra observed were mainly swell dominated with average value of the ratio of the two spectral peaks around 0.6 and the average value of the difference between peak frequencies around $0.09 \mathrm{~Hz}$. Even though the spectra were having two peaks, Kumar et al. (2003) found that Scott and ScottWiegel spectra estimate the maximum spectral energy density reasonably well except during the high wave along the Indian coast. Off Goa, TMA spectrum (Bouws et al., 1985) matched the observed sea spectra well when the sea breeze was active (Neetu et al., 2006) and during this period, $H_{\mathrm{m} 0}$ was less than $2 \mathrm{~m}$. For high waves, it was found that TMA model, without modifying the model parameters; over predict the maximum spectral energy, similar to the JONSWAP model (Hasselmann et al., 1973). Kumar and Kumar (2008) found that at different water depth (12 to $70 \mathrm{~m}$ ) around the Indian coast, the JONSWAP spectra with the modified spectral parameters represented the measured spectra well for $H_{\mathrm{m} 0}$ more than $2 \mathrm{~m}$.

A number of studies were carried out to understand wave generation and wave growth (Phillips, 1957; Miles, 1957; Donelan and Hui, 1990). Young (1997) studied the effect of fetch length on the growth rate in a finite depth and found that for longer fetches, the growth rate decreases in finite depth compared to deep water. Wave characteristics during growth and decay off the Goa coast at $80 \mathrm{~m}$ water depth during

Published by Copernicus Publications on behalf of the European Geosciences Union. 


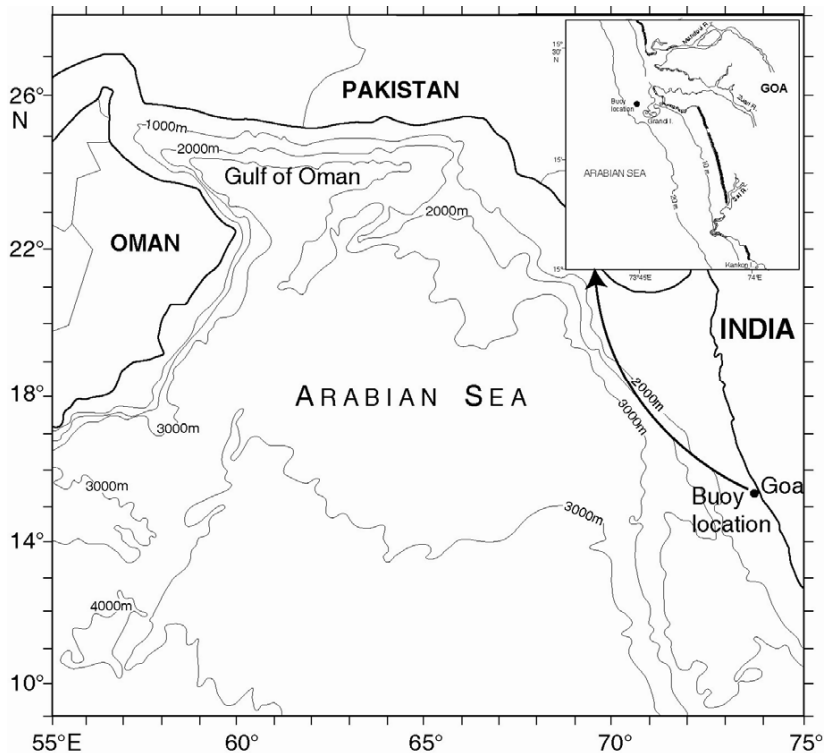

Fig. 1. Wave measurement location in the north Indian Ocean. The water depth at the measurement location is $14 \mathrm{~m}$.

17-24 March 1986 was studied by Rao and Baba (1996). Wind sea growth and dissipation in a swell-dominated open ocean environment is investigated by Hanson and Phillips (1999). Hanson and Phillips (1999) and Violante-Carvalho et al. (2004) have found no obvious influence of swell on the wind sea growth rates. When the measurement location is close to the coast, the wave conditions will be influenced by sea and land breeze, shallow water depth and currents. The horizontal extent of the sea/land breeze circulation over the Arabian Sea is observed upto about $80-100 \mathrm{~km}$ (Bala Subrahamanyam et al., 2001). Aparna et al. (2005) observed that off Goa coast, during February-April, the seaward extent of the sea breeze was about $180 \mathrm{~km}$.

The knowledge on characteristics of waves in the shallow waters off India during the onset of summer monsoon are required for prediction of waves using wave models and at present are not known. Hence a study was carried out to know the variations in wave characteristics during the wave growth by deploying a directional waverider buoy at $14 \mathrm{~m}$ water depth off the coast of Goa, west coast of India.

\section{Methods}

Waves in the open ocean at $14 \mathrm{~m}$ water depth off Goa at a location $15^{\circ} 24^{\prime} 21^{\prime \prime} \mathrm{N} ; 73^{\circ} 45^{\prime} 20^{\prime \prime} \mathrm{E}$ (Fig. 1) was measured using the Datawell directional waverider buoy (Barstow and Kollstad, 1991) during 24 May 2006 to 5 June 2006 for 12 days. The wave data were recorded continuously at $1.28 \mathrm{~Hz}$. From the recorded heave data covering 20 min duration, the wave spectrum was obtained through Fast Fourier transform (FFT). FFT of 6 series, each consisting of 256 measured ver- tical elevations of the buoy data (heave), were added to obtain the spectra. The high frequency cut off was set at $0.58 \mathrm{~Hz}$ and the resolution was $0.005 \mathrm{~Hz}$. Heave was measured in the range of -20 to $20 \mathrm{~m}$ with a resolution of $1 \mathrm{~cm}$ and an accuracy of $3 \%$. When the moored buoy follows the waves, the force of the mooring line may change resulting in a maximum error of $1.5 \%$ in the measurement of surface elevation. Also, if the wavelength is less than $5 \mathrm{~m}$, the buoy will not follow the wave amplitude and hence will not measure the wave. The significant wave height $\left(H_{\mathrm{m} 0}\right)$ and the mean wave period $\left(T m_{02}\right)$ were obtained from the spectral analysis. The period corresponding to the maximum spectral energy density is referred as spectral peak period $\left(T_{\mathrm{p}}\right)$ and is estimated from the wave spectrum. The sea and swell from the measured data was separated following Portilla et al. (2009). Other parameters obtained were spectral width parameter $(\varepsilon)$ based on spectral analysis (Cartwright and Longuet-Higgins, 1956), spectral narrowness parameter $(v)$ and spectral peakedness parameter $\left(Q_{\mathrm{p}}\right)($ Goda, 1970) as given below. The spectral width and narrowness parameter varies from 0 to 1 , and will have smaller values for narrower spectra. Spectral peakedness parameter will have higher values for narrow spectra.

$$
\begin{aligned}
& \varepsilon=\sqrt{1-\frac{m_{2}^{2}}{m_{0} m_{4}}} \\
& \nu=\sqrt{\frac{m_{0} m_{2}}{m_{1}^{2}}-1} \\
& Q_{\mathrm{p}}=\frac{2}{m_{0}^{2}} \int_{0}^{\infty} f S^{2}(f) d f
\end{aligned}
$$

Where $m_{n}$ is the $n$-th order spectral moment and is given by,

$m_{n}=\int_{0}^{\infty} f^{n} S(f) d f$

$n=0,1,2$ and $4 ; S(f)$ is the spectral energy density at frequency $f$.

Zero-crossing analysis of the surface elevation time series was used to estimate $H_{1 / 3}, H_{1 / 10}$ and maximum wave height $\left(H_{\max }\right)$.

The wind data recorded by the NDBP buoy $\left(15^{\circ} 24^{\prime} 7^{\prime \prime} \mathrm{N}\right.$ and $73^{\circ} 45^{\prime} 43^{\prime \prime} \mathrm{E}$ ) at $3 \mathrm{~m}$ above sea level was also used in the analysis. The NDBP buoy was at a distance of around $0.9 \mathrm{~km}$ from the wave measurement location and was at the same depth contour $(14 \mathrm{~m})$ of the deployed wave buoy. The time reference in the paper is in Universal Time Coordinated (UTC). The local time (IST) is $5.5 \mathrm{~h}$ more than the UTC. The wind speeds from the buoy $(U z)$ were transformed to wind speeds at $10 \mathrm{~m}$ elevation $\left(U_{10}\right)$, using Prandtl 1/7 law approximation,

$U_{10} / U z=(10 / z)^{1 / 7}$

where $z$ is the height at which the wind is measured, and $U_{10}$ and $U z$ are the wind speeds at $10 \mathrm{~m}$ and $z \mathrm{~m}$ heights. 

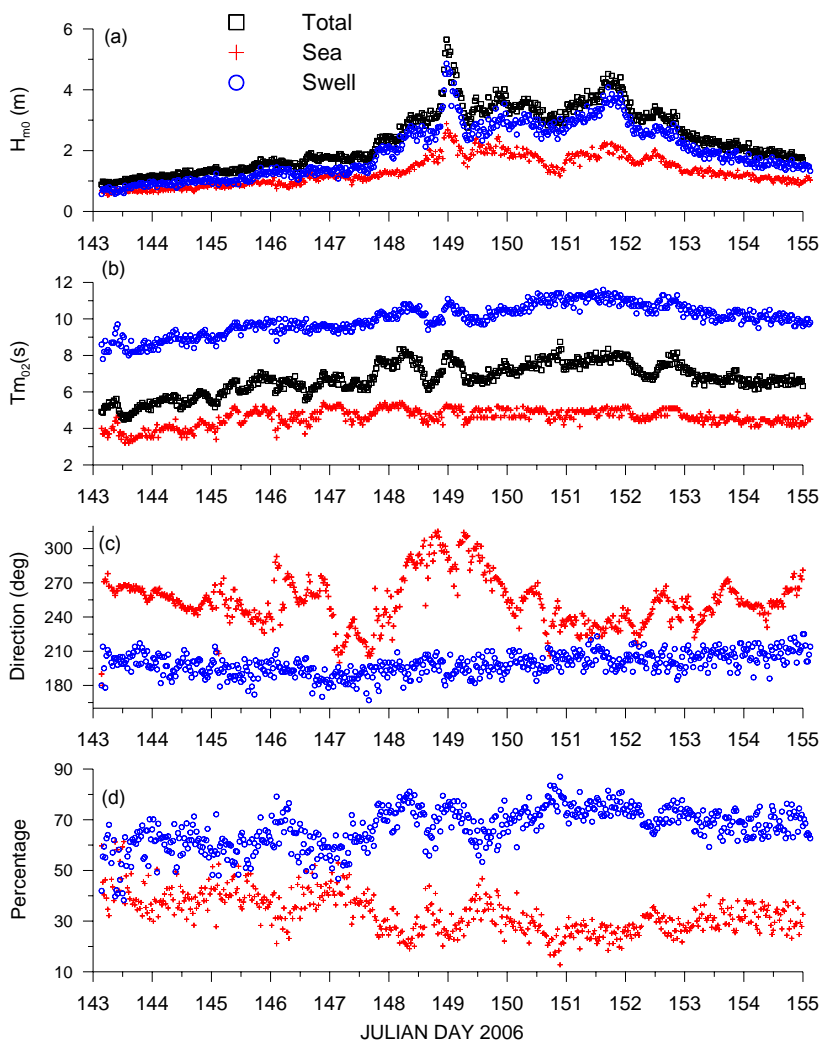

Fig. 2. Variation of (a) Significant wave height, sea and swell height. (b) Average mean wave period, mean wave period of sea, mean wave period of swell. (c) Mean wave direction of swell and mean wave direction of sea. (d) Percentage of sea and swell.

The logarithmic approximation is more accurate and universal, but the Prandtl 1/7 approximation (Streeter et al., 1998) is more convenient to apply and commonly used (Kamphuis, 2001; Resio et al., 2002). Also the logarithmic approximation requires information on the roughness parameter which is unknown for the study location.

\section{Results and discussions}

To identify the swell components from the measured data, the locally generated waves and the swell were separated. $H_{\mathrm{m} 0}$ upto $5.65 \mathrm{~m}$ was recorded during the measurement period (Fig. 2a). $H_{\mathrm{m} 0}$ increased from 2 to $5.65 \mathrm{~m}$ in $29 \mathrm{~h}$. The increase of $H_{\mathrm{m} 0}$ from 3 to $5.65 \mathrm{~m}$ took $15 \mathrm{~h}$ and the decay from 5.65 to $3 \mathrm{~m}$ took only $7.5 \mathrm{~h}$. Mean $T m_{02}$ was $7 \mathrm{~s}$ (Table 1 ) and the mean period of swell was $10 \mathrm{~s}$ (Fig. 2b). The measured waves were predominantly swells arriving from south and south-west and seas were from south-west to north-west (Fig. 2c). During the measurement period, $67 \%$ of the wave height was due to the swells and the remaining was due to the seas (Fig. 2d). Good positive correlation (correlation coefficient $=0.96$ ) was observed between $H_{\mathrm{m} 0}$ and $H_{\max }$. The concept of statistically stationary wave heights was proposed by Longuet-Higgins (1952) and as per this concept; the ratios of significant wave parameters are expected to be constant with the theoretical value proposed for $H_{\max } / H_{1 / 3}$ as 1.53 . Our analyses show that the ratio between $H_{\max }$ and $H_{\mathrm{m} 0}$ is 1.65 and is similar to the earlier reported results (Dattatri et al., 1979; Kumar, 2006). The maximum $H_{\max }$ recorded is $8 \mathrm{~m}$ and is 0.57 times the water depth. When waves are propagating in water of constant depth, Nelson (1994) showed that for shallow water waves the upper limit value for the ratio of $H_{\max }$ to water depth is 0.55 and is less than that often used in engineering practice (0.78). Massel (1996) reported that the ratio of $H_{\max }$ to water depth is less than 0.6. The value of 0.57 observed in the present study is similar to the observation of Massel (1996) and is slightly higher than the value proposed by Nelson (1994). For the present data, significant wave height based on zero crossing analysis $\left(H_{1 / 3}\right)$ was found to be $3.75 \sqrt{ } \mathrm{m} 0$. In practice, $H_{\mathrm{m} 0}$ is operationally defined as $4 \sqrt{ } \mathrm{m} 0$. For deep-water narrow band spectra, $H_{1 / 3}$ and $H_{\mathrm{m} 0}$ are equivalent estimates of significant wave height (Sarpkaya and Isaacson, 1981). When a narrow frequency spectrum is assumed, all characteristic wave heights are theoretically proportional to the standard deviation of the water surface. Goda (1979) analysed field data and found that for wind-driven waves in deep water, the ratio is approximately 3.8 instead of the narrow-band value of 4 which gives a reduction of $5 \%$. The reduction in present case is $6.2 \%$ and the reduction is due to the presence of sea and swells in the measured data which makes the wave spectrum relatively broad banded. For wind-driven sea waves, the assumption of a narrow-banded frequency spectrum is no longer valid. In deep water, the Rayleigh distribution still holds to a very good approximation for the zero-crossing wave heights (Longuet-Higgins, 1980), but the ratios of wave height to standard deviation have to be reduced to account for the finite frequency bandwidth. We have found $H_{1 / 10} / H_{1 / 3}$ to be 1.25 and were slightly lower than the Rayleigh value of 1.275 due to the shallow water effects.

Guedes Soares et al. (2004) showed that in addition to individual wave parameters, the asymmetry of waves can be described by the statistics of the time series, such as the skewness and kurtosis. Linear sea states will have no skewness and the positive skewness value indicate that the wave crests are bigger than the troughs. Present study showed that the skewness varied from -0.12 to 0.22 with a mean value of 0.05 . The high waves $\left(H_{\mathrm{m} 0}>4 \mathrm{~m}\right)$ were associated with high skewness value $(\approx 0.2)$. The kurtosis varied from -0.37 to 0.77 . The correlation between the abnormality index (ratio of $H_{\max }$ to $H_{\mathrm{m} 0}$ ) and the kurtosis of the sea surface elevation was 0.6. The dependence of the abnormality index on the kurtosis agrees with the results of Guedes Soares et al. (2004). The mean value of the sea surface elevation during $30 \mathrm{~min}$ interval varied from -0.003 to $0.003 \mathrm{~m}$ and the average value for all the data is $0.1 \times 10^{-4} \mathrm{~m}$ indicating that the height of crest and the trough were nearly equal. 
Table 1. Range and average value of wave parameters during the onset of summer monsoon at $14 \mathrm{~m}$ water depth.

\begin{tabular}{lccc}
\hline Wave parameter & Range & Average & Standard deviation \\
\hline Significant wave height, $H_{\mathrm{m} 0}(\mathrm{~m})$ & $0.9-5.7$ & 2.4 & 0.9 \\
Significant wave height of sea, $H_{\mathrm{ss}}(\mathrm{m})$ & $0.5-2.9$ & 1.3 & 0.5 \\
Significant wave height of swell, $H_{\mathrm{sw}}(\mathrm{m})$ & $0.6-4.9$ & 2.0 & 0.9 \\
Maximum wave height $(\mathrm{m})$ & $1.3-8.0$ & 3.4 & 1.4 \\
Mean wave period, $T m_{02}(\mathrm{~s})$ & $4.5-8.7$ & 6.7 & 0.8 \\
Mean wave period of sea, $T m_{02 \mathrm{~s}}(\mathrm{~s})$ & $3.2-5.4$ & 4.6 & 0.5 \\
Mean wave period of swell, $T m_{02 \mathrm{sw}}(\mathrm{s})$ & $7.8-11.6$ & 10.0 & 0.8 \\
Wave period corresponding to $H_{\mathrm{max}}(\mathrm{s})$ & $3.9-13.3$ & 9.2 & 1.3 \\
Peak wave period, $T_{\mathrm{p}}(\mathrm{s})$ & $6.7-14.3$ & 10.9 & 1.4 \\
Spectral peakedness parameter, $Q_{\mathrm{p}}$ & $1.4-3.6$ & 2.2 & 0.4 \\
Spectral width parameter, $\varepsilon$ & $0.7-0.9$ & 0.8 & 0.02 \\
Spectral narrowness parameter, $v$ & $0.4-0.6$ & 0.5 & 0.04 \\
Peak wave direction, $\theta_{\mathrm{p}}(\mathrm{deg})$ & $233-287$ & 255 & 9 \\
Mean wave direction of sea, $\theta_{\mathrm{se}}(\mathrm{deg})$ & $180-315$ & 254 & 22 \\
Mean wave direction of swell, $\theta_{\mathrm{sw}}(\mathrm{deg})$ & $167-225$ & 199 & 10 \\
Percentage of sea & $13-61$ & 33 & 8 \\
Percentage of swell & $39-87$ & 67 & 8 \\
Wave length $(\mathrm{m})$ & $31-90$ & 63 & 12 \\
Maximum spectral energy $\left(\mathrm{m}^{2} \mathrm{~Hz}^{-1}\right)$ & $0.4-63.3$ & 11.1 & 107.6 \\
Wind speed $\left(\mathrm{m} \mathrm{s}^{-1}\right)$ & $0.1-13.7$ & 4.3 & 2.7 \\
Inverse wave age $\left(U_{10} / C_{\mathrm{p}}\right)$ & $0.009-1.05$ & 0.34 & 0.044 \\
\hline
\end{tabular}

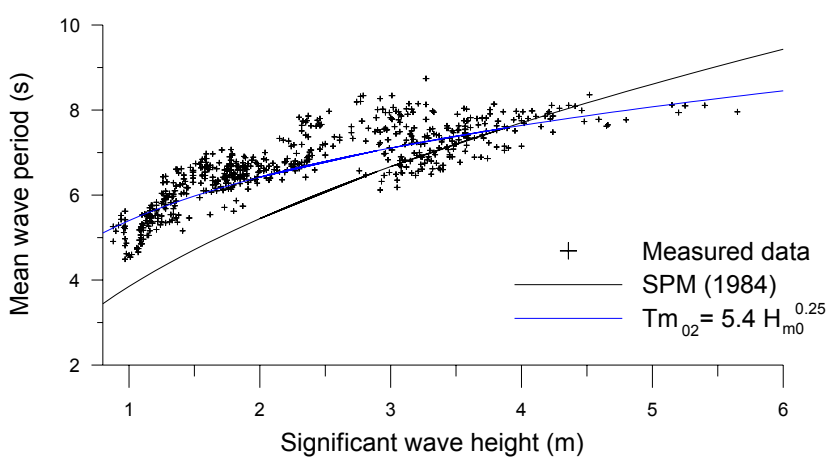

Fig. 3. Variation of mean wave period with significant wave height.

The average tidal range in the study area is $1.69 \mathrm{~m}$ during spring tide and $0.73 \mathrm{~m}$ during neap tide (Kumar et al., 2006). The currents measured at mid depth near the wave buoy location shows that the maximum u-component of currents (zonal) was $0.3 \mathrm{~m} / \mathrm{s}$ and the $\mathrm{v}$-component of current (meridional) was $0.4 \mathrm{~m} / \mathrm{s}$. Since the current speed is less than $0.4 \mathrm{~m} / \mathrm{s}$, the influence of currents on the waves will be less. The water depth at the wave measurement location is $14 \mathrm{~m}$ and hence the measured waves will have depth influence. Wave length associated with the mean wave period varied from 31 to $90 \mathrm{~m}, d / L$ ratio varied from 0.16 to 0.45 indicating that the measured waves are in the transitional water. The ratio of depth and wave length associated with the swell wave period varied from 0.11 to 0.18 indicating that the measured waves are in the transitional water. But $21 \%$ of the sea waves are in the deep water condition. Hence the waves measured are the transformed waves and the wave height and the wave direction measured will be different than that will be in the deep water.

Goda (1988) observed that wave data with recording intervals of 6 or $12 \mathrm{~h}$ tend to miss the peaks of some storm events and can lead to underestimation of severe wave conditions. In the present case, the data was recorded at half hourly interval and the underestimation of maximum $H_{\mathrm{m} 0}$ with recording interval of 3, 6 and $12 \mathrm{~h}$ compared to half hourly interval are 8.8, 20.7 and $20.7 \%$. In order to compensate for this effect, Allen and Callaghan (1999) used a simple block adjustment factor of $7 \%$ for the $6 \mathrm{~h}$ recording interval data and $10 \%$ for the $12 \mathrm{~h}$ recording intervals to each peak $H_{\mathrm{m} 0}$ value. The adjustment factors used were found to be lower for the present data due to the fact that the present data set was during the growth of waves and hence the wave condition was changing rapidly.

In order to study the variation of $T m_{02}$ with $H_{\mathrm{m} 0}$, the scatter plot is presented (Fig. 3) and found that $T m_{02}$ follow the expression given below.

$T m_{02}=a H_{\mathrm{m} 0}^{b}$

Where $a=5.4$ and $b=0.25$.

Kamphuis (2001) presented the value of $a$ and $b$ for different locations as given below. 


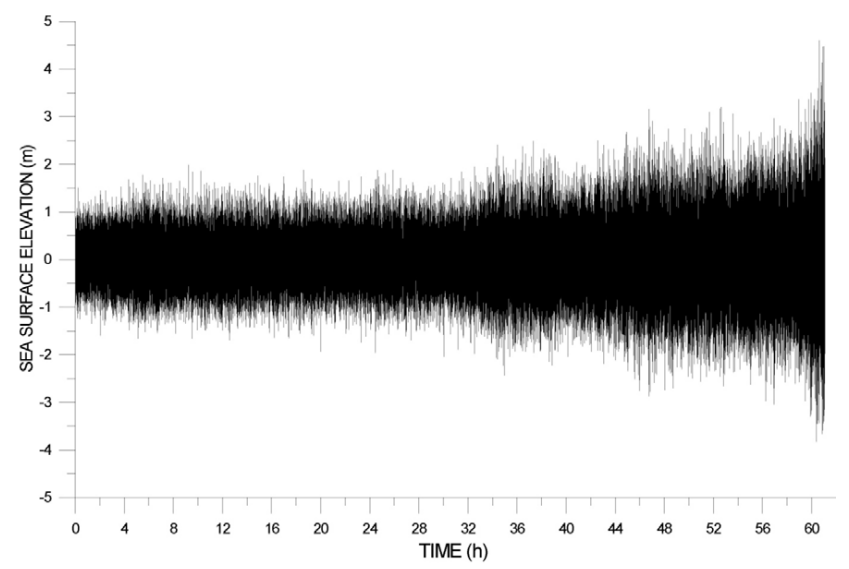

Fig. 4. Variation in sea surface elevation during 27 to 29 May 2006 (for $62 \mathrm{~h}$ ).

$$
\begin{aligned}
& a=3.54 ; b=0.6 \text { for Lake Huron } \\
& a=4.45 ; b=0.45 \text { for Lake Ontario } \\
& a=3.94 ; b=0.38 \text { for North Sea } \\
& a=4.04 ; b=0.47 \text { for Dubai } \\
& a=6.96 ; b=0.28 \text { for Israel }
\end{aligned}
$$

The variation of $T m_{02}$ with $H_{\mathrm{m} 0}$ was not following the relation proposed in SPM (1984). The high waves $\left(H_{\mathrm{m} 0}=5\right.$ to $6 \mathrm{~m}$ ) were associated with mean wave period of 7 to $8 \mathrm{~s}$ and the high wave period ( 8 to $9 \mathrm{~s}$ ) was associated with $H_{\mathrm{m} 0}$ varying from 2.5 to $3.5 \mathrm{~m}$ (Fig. 3) due to the fact that the measurements were carried out in open ocean and swells that have originated from a distant storm might have decayed with time resulting in low wave height whereas the wave period remains high.

The variation in sea surface elevation during 27 to 29 May 2006 is presented in Fig. 4. The wave height increased from 2 to $8 \mathrm{~m}$ during $60 \mathrm{~h}$. The peak wave direction (mean wave direction corresponding to the maximum spectral energy) decreased from $270^{\circ}$ to $240^{\circ}$ during the wave growth period (Fig. 5a). The peak mean wave directions at the high frequencies align with the westerly wind direction and gradually shift to south-westerly swell direction at low frequencies. During the study period, the wind speed $\left(U_{10}\right)$ ranged from 0.1 to $13.7 \mathrm{~m} / \mathrm{s}$ (Fig. 5b). The value of $H_{\mathrm{m} 0}$ more than $2 \mathrm{~m}$ when the local wind speed was less than $3 \mathrm{~m} / \mathrm{s}$ indicate the presence of swell along the west coast of India.

The shifting of peak frequency towards lower frequencies (from 0.12 to $0.08 \mathrm{~Hz}$ ) is noticed during $15 \mathrm{~h}$ on 24 May to $8 \mathrm{~h}$ on 29 May 2006, i.e. during the initial stage of wave growth (Fig. 5c). The peak frequency is uniform during 8 to $23 \mathrm{~h}$ on 29 May 2006. The shifting of peak frequency towards the lower frequency is recognized as one of the wave growth characteristics. As a result of the dynamical processes the peak shifts to lower frequencies and the spectrum broadens. Liu et al. (2007) presented complete episode of wave growth process from $10 \mathrm{~h}$ of continuous and
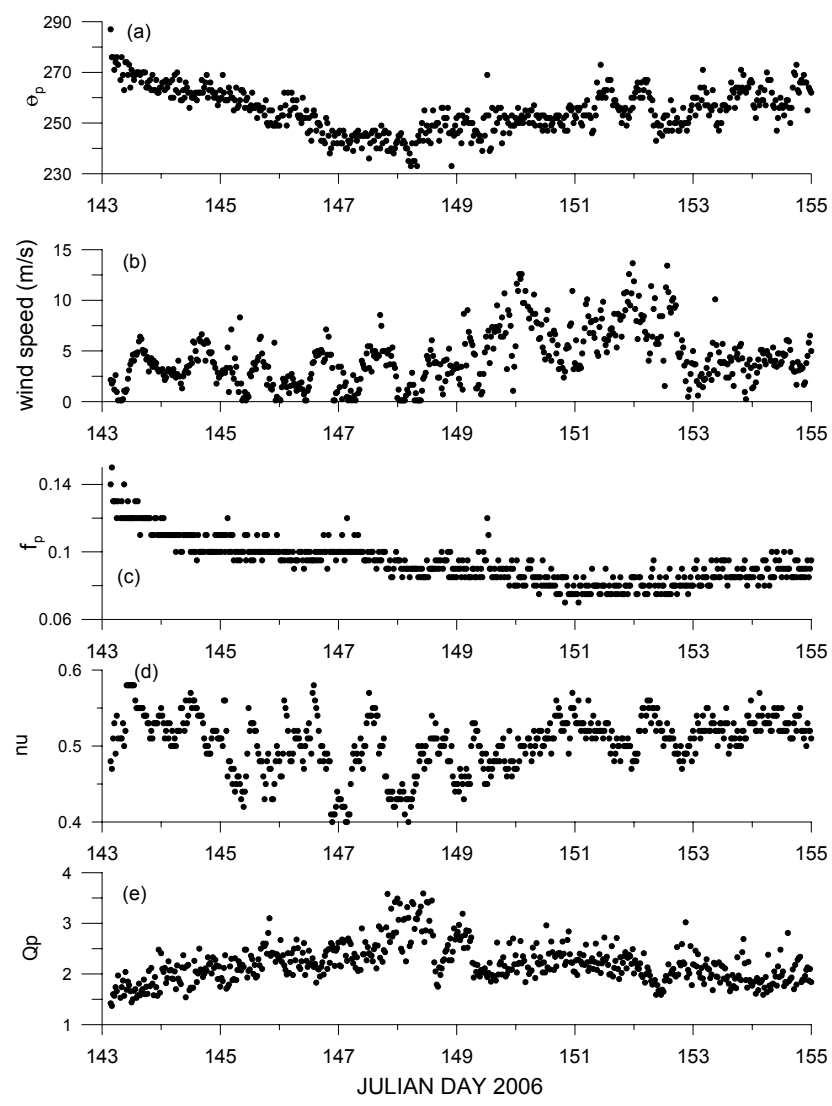

Fig. 5. Variation of (a) peak wave direction, (b) wind speed, (c) peak frequency, (d) spectral narrowness parameter and (e) spectral peakedness parameter.

uninterrupted wind wave measurements and found that the process of shifting toward lower frequency is not persistent and it is more of an incipient occurrence at the early stage of the growth. As the waves continue to grow, the shifts become less conspicuous and proceeded to coalesce into a unified predominant peak frequency during the vigorous wave growth stage.

During the measurements, the spectral narrowness parameter $(v)$ has a mean value of around 0.5 (Table 1) and is marginally high (around 0.55) when bimodal nature of the spectrum consisting of low-energy swell from the north Indian Ocean and a high frequency local component was present. When the wave height was high, $v$ was relatively small with value around 0.44 (Fig. 5d) indicating that the wave spectrum was relatively narrow banded during high waves. The spectral width parameter $(\varepsilon)$ varied from 0.74 to 0.85 . During the high waves, the value of $\varepsilon$ was around 0.78. The value of the spectral peakedness parameter $\left(Q_{\mathrm{p}}\right)$ varied from 2.5 to 3 for high waves (Fig. 5e). Large values of $Q_{\mathrm{p}}$ also indicate the wave spectrum is narrow banded for high waves. 


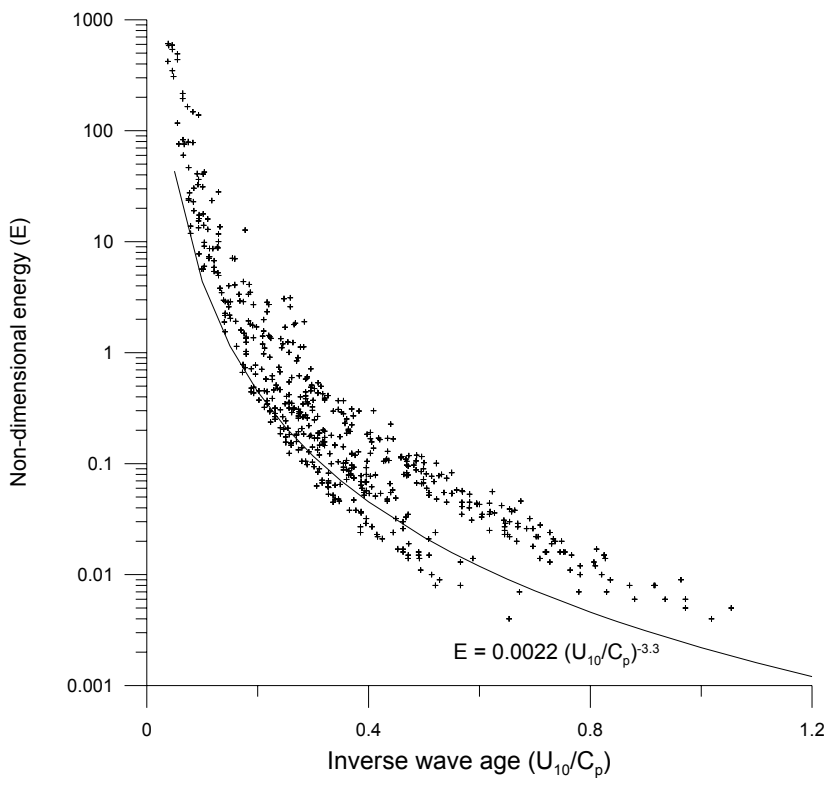

Fig. 6. Variation of non-dimensional energy with inverse wave age.

Since the measurement location is just $3 \mathrm{~km}$ from the coast, the sea breeze and land breeze can influence the wave parameters. But the present data collected during the onset of monsoon does not show significant influence of sea breeze on the wave parameters. Mandal and Halder (1992) observed that during the summer monsoon (May-September), the wind field is dominated by the large-scale atmospheric circulation and the winds are westerly (inshore) along the west coast of India and there is practically no land or sea breeze when the monsoon is active, but a weak land and seabreeze system develops during a break in the monsoon.

The nature of sea state is identified based on the wave steepness $\left(H_{\mathrm{m} 0} / L\right)$ and the wave age $\left(C_{\mathrm{p}} / U_{10}\right)$, where $C_{\mathrm{p}}$ is the wave phase speed at peak frequency. Wave steepness is expressed as the ratio between the significant wave height and the wave length of the peak period. Thompson et al. (1984) classified ocean waves based on $\left(H_{\mathrm{m} 0} / L\right)$ as sea, young swell, mature swell and old swell. According to their classification, locally generated waves or sea waves have steepness values greater than 0.025 . In the present case, correlation between wave age and wave steepness is low and the waves steepness was greater than 0.025 . Young sea is defined when wave ages $<10$ and an old sea is defined as wave ages $>25$. Wave age of the measured data is less than 25 with most values less than 10 . Hence the waves are young sea with presence of swells. Positive correlation is found between wind speed $\left(U_{10}\right)$ and $H_{\mathrm{m} 0}$. When the wind and wave directions are opposite from each other, the wind speed applies an opposing stress against the waves and therefore the wave height growth is negative.

Donelan et al. (1993) proposed that $U_{10} / C_{\mathrm{p}}=0.83$ corresponds to the value of the spectrum at full development, where the spectral components below this value are classified as swell and above as wind sea. In the present case, only $3 \%$ of the waves have inverse wave age more than 0.83 (Fig. 6) which indicates that the pure wind sea was very less. In the open ocean, where most wave systems are close to being fully developed, the variation in wave age is small and becomes of less importance. Thus, swell has been proposed as a possible contributing factor to altering the growth rate of wind-sea in mixed wave conditions. In this context, the relative direction between wind and swell is crucial (Donelan et al., 1992; Drennan et al., 1999; Kudryavtsev and Makin, 2004). The non-dimensional energy $\left[E=H_{\mathrm{m} 0}^{2} \mathrm{~g}^{2} /\left(16 U_{10}^{4}\right)\right]$ was slightly higher than the value proposed by Donelan et al. (1992).

Even though, high local wind (upto $13 \mathrm{~m} / \mathrm{s}$ ) was present, the measured waves were predominantly swells due to the fact that energy of the wind sea reduces and that of the swell increases when the swell is added to the system (Donelan, 1987).

The estimated fetch based on JONSWAP peak-frequencyfetch relationship (Long and Resio, 2007) for the high waves varies from 80 to $100 \mathrm{~km}$. The peak wave direction corresponding to the high waves was 240 to $260^{\circ}$. On examining the NCEP wind (Kalnay et al., 1996) in the Arabian Sea, it is found that strong westerly winds was present at between longitude $72^{\circ}$ and $72.5^{\circ}$ along the latitude $12.5^{\circ}$ and it has created the high waves and the phase difference between the wind and the wave is $20 \mathrm{~h}$. The propagation speed of the wave is between 9 and $10 \mathrm{~m} / \mathrm{s}$.

\section{Conclusions}

The high waves $\left(H_{\mathrm{m} 0}=5\right.$ to $\left.6 \mathrm{~m}\right)$ were associated with mean wave period of 7 to $8 \mathrm{~s}$ and the high wave period ( 8 to $9 \mathrm{~s}$ ) was associated with $H_{\mathrm{m} 0}$ varying from 2.5 to $3.5 \mathrm{~m}$ due to the fact that the measurements were carried out in open ocean and swells that have originated from a distant storm might have decayed with time resulting in low wave height whereas the wave period remains high.

The water depth at the measurement location is $14 \mathrm{~m}$ and hence waves measured are the transformed waves and the wave height and the wave direction measured will be different than that will be in the deep water.

The ratio of maximum $H_{\max }$ to the water depth is 0.57 and this ratio is similar to the observation of Massel (1996) and is slightly higher than the value proposed by Nelson (1994).

Wave age is less than 25 with most values less than 10 and hence the waves during the onset of summer monsoon are young sea with presence of swells.

Spectral narrowness parameter was around 0.44 when the wave height was high and slightly large (around 0.55 ) when bimodal nature of the spectrum consisting of low-energy swell from north Indian Ocean and a high frequency local component was present. 
During the high waves, the fetch estimated based on JONSWAP peak-frequency-fetch relationship is from 80 to $100 \mathrm{~km}$ and it is found that strong westerly winds present at between longitude $72^{\circ}$ and $72.5^{\circ}$ along the latitude $12.5^{\circ}$ has created the high waves. The propagation speed of the wave is between 9 and $10 \mathrm{~m} / \mathrm{s}$.

Acknowledgements. Authors thank Satish R. Shetye, Director, NIO and Satheesh C. Shenoi, Director, INCOIS for providing facilities and encouragement. Also thank P. Pednekar, K. Ashok Kumar, R. Gowthaman, Ganesh N. Naik and Manohar Manohar for the help during the wave data collection. The data on wind speed and direction recorded by NDBP buoy was provided by National Institute of Ocean Technology, Chennai. This paper is NIO contribution number 4709 .

Topical Editor P. Drobinski thanks H. Branger for his help in evaluating this paper.

\section{References}

Allen, M. and Callaghan, J.: Extreme wave conditions for the south Queensland coastal region. Environment technical report (Queensland. Environmental Protection Agency), 32, 1-7, 1999.

Aparna, M., Shetye, S. R., Shankar, D., Shenoi, S. S. C., Mehra, P., and Desai, R. G. P.: Estimating the seaward extent of sea breeze from QuikSCAT scatterometry, Geophys. Res. Lett., 32, L13601, doi:10.1029/2005GL023107, 2005.

Bala Subrahamanyam, D., Sen Gupta, K., Sudha Ravindran, and Praveena Krishnan: Study of sea breeze and land breeze along the west coast of Indian sub-continent over the latitude range $15^{\circ} \mathrm{N}$ to $8^{\circ} \mathrm{N}$ during INDOEX IFP-99 (SK-141) cruise, Curr. Sci. India, 80, 85-88, 2001.

Barstow, S. B. and Kollstad, T.: Field trials of the directional waverider, in: Proceedings of the First International Offshore and Polar Engineering Conference, Edinburgh, III, 55-63, 1991.

Bouws, E., Günther, H., Rosenthal, W., and Vincent, C. L.: Similarity of the Wind Wave Spectrum in Finite Depth Water. 1. Spectral Form, J. Geophys. Res., 90(C1), 975-986, 1985.

Cartwright, D. E. and Longuet-Higgins, M. S.: The statistical distribution of the maxima of a random function, Proc. Roy. Soc. London, A 237, 212-232, 1956.

Dattatri, J., Raman, H., and Jothi Shankar, N.: Height and period distribution for waves off Mangalore Harbour - west coast of India, J. Geophys. Res., 84(C7), 3767-3772, 1979.

Donelan, M. A.: The effect of swell on the growth of wind waves, Johns Hopkins APL Technical Digest, 8(1), 18-23, 1987.

Donelan, M. A., Skafel, M., Graber, H., Liu, P., and Schwab, D.: On the growth rate of wind-generated waves, Atmos. Ocean, 30(3), 457-478, 1992.

Donelan, M. A. and Hui, W. H.: Mechanics of ocean surface waves, in: Surface Waves and Fluxes, edited by: Geernaert, G. and Plant, W., Kluwer Academic Publishers, The Netherlands, 1336, 1990.

Donelan, M., Dobsen, F., Smith, S., and Anderson, R.: On the dependence of sea surface roughness on wave development, J. Phys. Oceanogr., 23, 2143-2149, 1993.

Drennan, W., Graber, H., and Donelan, M.: Evidence for the effects of swell and unsteady winds on marine wind stress, J. Phys. Oceanogr., 29, 1853-1864, 1999.
Goda, Y.: On the Methodology of Selecting Design Wave Height, in: Proceedings 21st Coastal Engineering Conference, ASCE, 899-913, 1988.

Goda, Y.: Numerical experiments on wave statistics with spectral simulation, in: Report Port and Harbour Research Institute, Japan, 9, 3-57, 1970.

Goda, Y.: A review on statistical interpretation of wave data, in: Report of the Port and Harbour Research Institute, Japan, 18, 532, 1979.

Guedes Soares, C., Cherneva, Z., and Antao, E. M.: Steepness and asymmetry of the largest waves in storm sea states, Ocean Eng., 31, 1147-1167, 2004.

Hanson, J. L. and Phillips, O. M.: Wind sea growth and dissipation in the open ocean, J. Phys. Oceanogr., 29, 1633-1648, 1999.

Hasselmann, K., Barnett, T. P., Bouws, F., Carlson, H., Cartwright, D. E., Enke, K., Ewing, J. A., Gienapp, H., Hasselmann, D. E., Krusemann, P., Meerburg, A., Müller, P., Olbers, D. J., Richter, K., Sell, W., and Walden, H.: Measurements of wind-wave growth and swell decay during the Joint North Sea Wave Project (JONSWAP), Dtsch. Hydrogr. Z. Suppl., A8(12), 95, 1973.

Kalnay, E., Kanamitsu, M., Kistler, R., Collins, W., Deaven, D., Gandin, L., Iredell, S., Saha, G., White, J., Woollen, Y., Zhu, A., Leetmaa, B., Reynolds, M., Chelliah, W., Ebisuzaki, W., Higgins, W., Janowiak, J., Mo, K. C., Ropelewski, C., Wang, J., Leetmaa, A., Reynolds, R., Jenne, R., and Joseph, D.: The NCEP/NCAR 40-year reanalysis project, B. Am. Meteorol. Soc., 77(3), 437-471, 1996.

Kamphuis, W.: Introduction to Coastal Engineering and Management, World Scientific Publishing Company, 1-472, 2001.

Kudryavtsev, V. and Makin, V.: Impact of swell on the marine atmospheric boundary layer, J. Phys. Oceanogr., 34, 934-949, 2004.

Kumar, V. S., Anand, N. M., Kumar, K. A., and Mandal, S.: Multipeakedness and groupiness of shallow water waves along Indian coast, J. Coastal Res., 19, 1052-1065, 2003.

Kumar, V. S. and Anand, N. M.: Variations in wave direction estimated using first and second order Fourier coefficients, Ocean Eng., 31, 2105-2119, 2004.

Kumar, V. S.: Variation of wave directional spread parameters along the Indian coast, Appl. Ocean Res., 28, 98-103, 2006.

Kumar, V. S. and Kumar, K. A.: Spectral representation of high shallow water waves, Ocean Eng., 35, 900-911, 2008.

Kumar, V. S., Pathak, K. C., Pednekar, P., Raju, N. S. N., and Gowthaman, R.: Coastal processes along the Indian coastline, Curr. Sci. India, 91(4), 530-536, 2006.

Liu, P. C., Chen-Han Tsai, C. C., and Chen, H. S.: On the growth of ocean waves, Ocean Eng., 34, 1472-1480, 2007.

Long, C. E. and Resio, D. T.: Wind wave spectral observation in Currituk sound, North Carolina, J. Geophys. Res., 112, C05001, doi:10.1029/2006JC003835, 2007.

Longuet-Higgins, M. S.: On Statistical Distribution of the Heights of Sea Waves, J. Mar. Res., 11, 245-266, 1952.

Longuet-Higgins, M. S.: On the Distribution of the Heights of Sea Waves; Some Effects of Nonlinearity and Finite Band Width, J. Geophys. Res., 85(C8), 1519-1528, 1980.

Mandal, J. C. and Halder, S. R.: Sea breeze like cloud-free zones during monsoon months, Mausam, 43, 163-168, 1992.

Massel, S. R.: On the largest wave height in water of constant depth, Ocean Eng., 23, 553-573, 1996.

Miles, J.: On the generation of surface waves by shear flows, J. 
Fluid Mech., 3, 185-204, 1957.

Neetu, S., Shetye, S. R., and Chandramohan, P.: Impact of sea breeze on wind-seas off Goa, west coast of India, J. Earth Syst. Sci., 115, 229-234, 2006.

Nelson, R. C.: Depth limited design wave heights in very flat regions, Coastal Eng., 23, 43-59, 1994.

Phillips, O. M.: On the generation of waves by turbulent wind, J. Fluid Mech., 2, 417-445, 1957.

Portilla, J., Ocampo-Torres, F. J., and Monbaliu, J.: Spectral Partitioning and Identification of Wind Sea and Swell, J. Atmos. Oceanic Technol., 26, 117-122, 2009.

Rao, C. V. K. P. and Baba, M.: Observed wave characteristics during growth and decay: a case study, Cont. Shelf Res., 16, 1509-1520, 1996.

Resio, D., Bratos, S., and Thompson, E.: Meteorology and wave climate, in: Coastal Engineering Manual, Part II, Hydrodynamics, edited by: Vincent, L. and Demirbilek, Z., U.S. Army Corps of Engineers, Washington, D.C., Chapter II-2, Engineer Manual 1110-2-1100, 2002.
Sarpkaya, T. and Isaacson, M.: Mechanics of wave forces on offshore structures, Van Nostrand Reinhold, New York, 491-492, 1981.

Shore Protection Manual: U.S. Army Coastal Engineering Research Center, Department of the Army, Corps of Engineers, US Govt. Printing Office, Washington, D.C., USA, vols. 1 and 2, 1984.

Streeter, V. L., Wylie, E. B., and Bedford, K. W.: Fluid Mechanics. McGraw-Hill, Singapore, 1-740, 1998.

Thompson, T. S., Nelson, A. R., and Sedivy, D. G.: Wave group anatomy, in: Proceeding of 19th conference on Coastal engineering, American Society of Civil Engineers, 1, 661-677, 1984.

Violante-Carvalho, N., Ocampo-Torresb, F. J., and Robinson, I. S.: Buoy observations of the influence of swell on wind waves in the open ocean, Appl. Ocean Res., 26, 49-60, 2004.

Young, I. R.: The growth rate of finite depth wind-generated waves, Coastal Eng., 32, 181-195, 1997. 